Bentham open
CrossMark

RESEARCH ARTICLE

\title{
The Significance of Community Support for Survivors of a Natural Disaster
}

\author{
Marian S. Harris ${ }^{1, *}$, Ganita Musa ${ }^{2}$ and Ryan Brookman ${ }^{3}$ \\ ${ }^{1}$ University of Washington Tacoma Social Work and Criminal Justice Program 1900 Commerce Street Tacoma, WA \\ 98402-3100, USA \\ ${ }^{2}$ University of Washington Tacoma \& Child \& Family Therapist Southwest Youth and Family Services 4555 Delridge \\ Way SW Seattle, WA 98106, USA \\ ${ }^{3}$ University of Washington Tacoma School of Interdisciplinary Arts \& Sciences 1900 Commerce Street Tacoma, WA \\ 98402-3100, USA
}

\begin{abstract}
This community based participatory research study was conducted in Oso, WA. Ten survivors of the 2014 mudslide participated in a focus group and discussed their experiences before and after this natural disaster. Findings revealed that the majority of participants had feelings of confusion/redundancy and were still processing feelings of grief and loss at the time of the focus group. Another finding was the strong sense of community expressed by all participants and the high level of support participants provided to each other during and after the mudslide. The study also highlighted the need for mental health resources to be part of any disaster relief plan because survivors need emotional support. Finally, findings demonstrated the importance of outside relief organizations seeking input from community members prior to implementing disaster relief; findings highlighted the significance of utilizing the high level of knowledge regarding area landslides expressed by members of the Oso community.
\end{abstract}

Keywords: Community, Sense of community, Disaster relief, Physical community, Mental health, Social community, Mudslide, Community support, Oso, WA.

\section{LITERATURE REVIEW}

\section{Natural Disasters}

Natural disasters can have devastating consequences and leave lasting damage, requiring years to repair. In recent decades, there has been a large rise in both the number and impact of natural disasters. According to the World Bank (2013), between 1997 and 2006, the number of reported disasters grew by 60 percent, compared to the previous decade, from 4,241 to 6,806 . At the same time, the number of reported deaths doubled, from more than 600,000 to over 1.2 million; more than 200 million people a year have been directly affected through damage to homes, property, crops, livestock, and local infrastructure [1]. According to the World Health Organization (WHO, 2005), up to 50\% of the affected population may be expected to experience significant psychological distress and 5-10\% develop a diagnosable stress-related psychiatric disorder [2].

Munasinghe (2007) stated that the 2004 Asian Tsunami, triggered by a Richter scale 9 magnitude earthquake off the coast of Indonesia, was the most devastating disaster in recorded human history, killing over 250,000 people throughout South and East Asia [3]. According to Munasinghe (2007), in Sri Lanka alone, 35,000 Sri Lankans were killed (i.e., one in every 570 persons), and over half a million were displaced (i.e., one in every 40 persons). Few people were

\footnotetext{
* Address correspondence to this author at the University of Washington Tacoma Social Work and Criminal Justice Program 1900 Commerce Street Tacoma, WA 98402-3100, USA; Tel: (253) 692-4554; Fax: (253) 692-5825; E-mail: mh24@uw.edu
} 
untouched by this disaster; many saw loved ones, possessions, and communities washed out to sea, causing an unimaginable emotional and psychological burden. After ten years, victims of the disaster still struggle to understand the devastation and loss. In Oso, Washington on March 22, 2014 forty-three (43) people lost their lives to one of the deadliest mudslides in U.S. history which struck without any warning.

Wickerama and Kasper (2006) used surveys to collect data from 325 tsunami-exposed adolescents and mothers from two villages in South Sri Lanka to determine if higher PTSD and depressive symptoms among adolescents were associated with psychosocial losses, including prolonged displacement, social losses, and impairment of mother's mental health. Findings revealed that disaster exposure, including death of family and displacement, influence depression and PTSD [4]. Children are the most vulnerable of the group because, even if they don't have direct exposure, the caregiver's mental instability, combined with the loss of family members, has a tremendous effect on mental health.

Furthermore, findings by Wickrama and Kasper (2006) also revealed that the faster the families get assistance the less the disaster affects mental health. For example, the faster a school is rebuilt and children are able to get back to pretsunami social life the fewer mental health issues they face. This finding suggests that faster recovery to rebuild the communities that disasters strike is important in preventing psychiatric problems. Also, the key in assisting younger children after the tsunami is to provide support and resources for caregivers that will decrease the chance of mental illness and symptoms of PTSD. In a study reported by an Indian journal, women had a 6.35 times higher risk of having PTSD as compared to men when controlling for other variables. Yet the health effects are more pronounced and concentrated in the developing world which has contributed least to the problem but lacks the resources and infrastructure to tackle the problem.

Weissbecker and Jones (2014) argued that mental health problems are humanitarian crises that require attention. Mental illness resources have been missing from many disaster relief and development agencies' agendas [5]. Specifically, vulnerabilities such as poverty and poor health can contribute to mental health problems. Weissbecker and Jones (2014) also provided recommendations on how to include psychosocial programming in humanitarian settings in order to achieve better services and prevent mental illness for victims of natural disasters. Some of the recommendations include early assessment for stressors, actual population needs, and cultural contexts, filling training/service gaps, improving local participation, ownership, forging links with other humanitarian areas and programs, and building evidence-based best practices; all of the aforementioned recommendations are also important tools needed to build strong communities [5].

Any kind of natural disaster can impact a community economically and socially throughout the world. Manmade climate change can exacerbate natural disasters; however, people who are affected by the devastation of natural disasters are usually those who contribute least to the problem. Countries that are developing and poor often have difficulty recovering from any disaster because of lack of resources and the limitation of technology. In Oso, Washington on March 22, 2014, forty-three (43) people lost their lives to one of the deadliest landslides in U.S. history which struck without warning. According to Wartman (2016), "a landslide-the downslope movement of rock or soil-is a natural geologic process that forms and shapes landscapes. Slides occur when downward forces from gravity exceed the strength of soil or rock within a slope-in other words, when the weight of a hill slope becomes too much too bear" [6]. Survivors of this natural disaster are still encountering difficulty in their efforts to recover emotionally and economically.

\section{Definition of Community}

In most policy discussions the word community is often used and seldom defined. Is a community merely a place? What are the boundaries of a community? These questions present those in policy discussions with different entry points to the conversation based on their unique understanding of community. In this respect defining community is an essential task for policy makers and professionals to undertake when describing the impact of a policy on community or a community on a given policy.

The concept of community has often been discussed as being both descriptive and prescriptive (Frazer, 1999 [7]; Gusfield, 1975 [8]; McMillan and Chavis, 1986 [9]. On the one hand, community describes a value or ideal that is held by its members, while on the other hand it spells out the physical boundaries. These two aspects are often seen as competing for importance in policy decisions. Whether or not a community is viewed simply as a place or whether it is seen as a shared set of values puts different priorities on policy discussions. In terms of disaster relief it is important to 
recognize the interconnectedness of the two characteristics of community. This is vital in the discussion of disaster relief because both the physical community and the mental construction of the community are fractured. The result is a need to consider the community from a holistic viewpoint that takes into account reconstruction of the social bonds of the community in addition to the buildings. For most people communities are real. However, communities can be nurturing environments and can provide basic social, economic and emotional supports to individuals and families. According to Cohen (1985), community is defined as follows:

A system of values, norms, and moral codes which provoke a sense of identify within a bounded whole to its members... (S)tructures do not, in themselves, create meaning for people.... (Without meaning) many of the organizations designed to create "community" as palliative to anomie and alienation are doomed to failure [10].

Community can mean a geographic space, a geopolitical or civic entity, and a place of emotional identity. It is the emotional identity of community that gives it meaning for most people.

\section{Community-Driven Development}

In 1990 the World Bank faced criticism for the manner in which it had been carrying out development projects. The World Bank was viewed by many as an over-reaching byproduct of Neo-liberalism and instiller of a new form of colonialism in the developing world. In an attempt to address these concerns the World Bank (2015) turned away from endorsing projects with authority consolidated in the hands of the elite, towards projects that supported decentralization. The result was the adoption of Community-Driven Development (CDD); CDD "programs operate on the principles of transparency, participation, local-empowerment, demand-responsiveness, greater downward accountability, and enhanced local capacity" [11].

The International Fund for Agricultural Development (IFAD) also utilizes CDD as a guiding principle in their poverty reduction work in rural areas of the developing world. IFAD describes its interpretation of the approach as follows:

- CDD appreciates the role that community-based organizations (CBOs) play in decisions about the economic and social development processes that directly affect the livelihood of their members;

- CDD appreciates the development of a culture within public administration that views communities as subjects of change and development partners in their own right, rather than as mere receivers of the benefits of the benefits of public expenditure [12].

Both of the interpretations illustrate that CDD is a method of devising and implementing development policies rather than implementing an already formulated policy. This allows for those with experience in development and public policy sectors to craft ideas that benefit the people of the community; they are the ones ultimately deciding on which ideas get funded. In this manner we see the establishment of a public discourse that sees communities as the development partners referred to by IFAD.

CDD has become an increasingly popular approach in the developing world since its wide-scale introduction in the late 1990s. The World Bank (2015) has sponsored CDD programs in countries across the globe and is currently supporting CDD programs in 24 countries. Projects range from the Community Action for Nutrition project in Nepal, to a project in Jordan called Enhancing Community-Driven Legal Aid to the Poor, to the Community-Based Coastal Resource management and Sustainable Livelihoods in Mozambique. These projects are varied in scope as well as their goals which illustrate that the approach can be applied to a wide range of communities.

After any natural disaster there is a massive need for psychosocial support; therefore, it is important to include psychosocial support and resources into natural disaster relief immediately after a natural disaster in order to avoid the long-term impact of the disaster; this long-term impact can result in mental illness. Any persons affected by a catastrophic event like the tsunami of December 26, 2004 and the mudslide of March 22, 2014 in Oso, WA are exposed to extreme stressors immediately after the disaster strikes and for several years following the disaster.

Most survivors who are exposed to disasters are vulnerable to developing serious mental health problems Wickrama and Kaspar, 2006; Weissbecker and Jones, 2014; Lee, 2014 [13]. Psychosocial and mental health issues must be addressed, starting in the first few days and weeks of the relief efforts and must continue for many years. According to WHO (2005), "Psychosocial support programs and mental health care should be provided equitably to all in need, even if location is remote or demand is not actively expressed". In other words, government officials and relief agencies should not only focus on areas where accessibility is easy but should focus on areas with the most needs. This is 
especially relevant for the Oso mudslide survivors; this community did not have sufficient support due to geographic location resulting in limited accessibility to the area. Bado (2012) and the World Bank (2013) demonstrated that CDD is the most effective tool to reduce disaster risk and poverty by involving communities in relief projects; their studies revealed that any recovery response that does not consult affected communities regarding their needs and priorities can result in provision of the wrong support and resources which can be unsustainable for communities [14]. Therefore, CDD's mission is to empower communities and involve them in disaster relief projects in order to reduce the consequences of natural disasters.

\section{METHODOLOGY}

This exploratory-descriptive study examined the link between Community Driven Development and long-term goals following the 2014 mudslide in Oso, Washington. As a research team, we decided to do Community-Based Participatory research (CBPR). According to Horowitz, Robinson, and Seifer (2009), CBPR "engages the multiple stakeholders, including the public and community providers, who affect and are affected by a problem of concern. This collaborative approach to research equitably involves all partners in the research process and recognizes the unique strengths that each brings" [15]. There are three levels of community-based participatory research. At one level is research that gathers information directly from community members. Another level includes hiring of members of an affected group i.e. community members by researchers to collect data; these community members are hired because they are familiar with and known in the community. The third level involves recruitment of members of an affected group as partners in a research study. Our research team utilized the first level and gathered information directly from community members. Members of the Oso community were directly affected by the 2014 mudslide and were asked for their opinions about what they needed and what they thought would be of most help to them before and after the mudslide. This research study included qualitative and quantitative components and addressed the following research questions:

1. What are the resources provided to victims to reduce mental illness in the aftermath of natural disasters?

2. Can disaster relief lead to lasting benefits to the local community?

This research was supported by the Bamford Fellowship in Global Engagement (Bamford Foundation), Global Honors Program at the University of Washington Tacoma.

\section{Recruitment}

Prior to recruiting for this sample, an application for review of the study was submitted to a University of Washington Human Subjects Review Committee. We did not begin recruitment procedures until obtaining written approval on February 3, 2015 from the Human Subjects Review Committee to conduct this study. One of the researchers met with the manager of a local restaurant on January 23, 2015 to discuss the research study and to get a letter of cooperation from her to post a recruitment flyer on the bulletin board at the restaurant. A telephone script was developed by the researchers for use when talking to any individual who contacted the researchers and expressed an interest in voluntarily participating in the research study. Snowball sampling was also used to recruit potential participants i.e. the local fire chief informed residents about the study, including the recruitment flyer that was posted at the restaurant. Ten (10) individuals who met the inclusion criteria voluntarily agreed to participate in the research study.

\section{Data Collection}

Data were collected through a focus group of 10 survivors of the mudslide at a single point in time utilizing questions that were developed by members of the research team. The focus group was conducted in a private meeting room at a local restaurant to protect confidentiality of the participants. In particular this study aimed to explore the possible link between Community Development (CDD) and long-term community development goals, including poverty reduction, provision of mental health resources, and environmental resource protections. The study included quantitative and qualitative components. The sample represented only one ethnic group and was chosen because Whites were the dominant population in Oso at the time of the 2014 mudslide. Demographics from the U.S. Census Bureau (2010) about the Oso community are presented in Table 1 [16].

The researchers began the focus group by introducing themselves. All participants introduced themselves. Each participant was asked if he/she voluntarily agreed to participate in the study. One of the researchers explained the purpose, procedures, benefits and risks of the study. Each participant read and discussed the Consent for Participation in 
a Research Study Form with members of the research team. All participants signed two copies of the Consent Form after assuring members of the research team that they understood the form and after questions posed by participants were answered. One copy of the consent form was given to each participant and the second copy was kept by members of the research team. Each participant completed a Demographic Information Form. Questions were asked during the focus group by each member of the research team via a rotating system. All responses were audio-taped. The focus group lasted two hours.

Table 1. 2010 Statistics for Oso, Washington.

\begin{tabular}{|l|c|}
\hline \multicolumn{1}{|c|}{ Race } & Number \\
\hline American Indian and Alaska Native Alone & 1 \\
\hline Asian alone & 1 \\
\hline Black or African American & 0.56 \\
\hline Some other race alone & 0.56 \\
\hline Two or more races & 0.56 \\
\hline White & 3.33 \\
\hline
\end{tabular}

Total Males: 91 (60.4\%), Total Females: 89 (39.6\%) U. S. Census Bureau -2010 [16].

\section{Sample}

A purposive sampling method (specifically, criterion sampling) was used to recruit ten (10) individuals who met the following criteria: (a) 18-85 years of age; (b) resident of Oso, WA at the time of the 2014 mudslide; and (c) able to speak English. Additionally, a diverse sample was sought including both males and females drawn from multiple racial and ethnic groups. However, although males and females were included in the sample, there were no people of color in the sample. The sample represented only one ethnic group and was chosen because Whites were the dominant population in Oso at the time of the 2014 mudslide.

\section{Description of Sample}

Three participants identified as female and seven identified as male. The age range was 30-68 with a mean age of 55.0. All participants identified as white. Income ranged from $\$ 0-\$ 85,000$ with a mean income of $\$ 36,400$. Nine participants were married and one participant was single. Educational background varied among the participants (1M.S.; 2-B.A.; 1-2 years of college; 4-high school diploma; 1-1 year of college and 1-education unknown. Five participants stated no religious affiliation. Other participants identified their religious affiliation as follows: 2-Christian; 1-Catholic; 1-Faith-Filled; and 1-Protestant. The range of occupations is as follows: mechanic/firefighter-1; ranch hand-1; ranch manager-1; secretary-1; self-employed-1; support staff supervisor-1; truck driver-1; and - unknown-1. There were 2 retired participants.

\section{Data Analysis}

Demographic data from the Demographic Information Form were described for the participants and a frequency distribution of the sample was developed. According to Bryman (2004), content analysis is defined as follows:

An approach to documents that emphasizes the role of the investigator in the construction of the meaning of and in texts. There is an emphasis on allowing categories to emerge out of data and on recognizing the significance for understanding the meaning of the context in which an item being analyzed (and the categories derived from it) appeared [17].

All data collected via the focus group questions were typed verbatim by one of the researchers; data were content analyzed for identification of the themes that emerged in the narrative responses of participants during the focus group. The researchers were interested in the latent content of the communication i.e. its underlying meanings. According to Rubin and Babbie (2014), "content analysis is a research method for studying virtually any form of communication, consisting primarily of coding and tabulating the occurrences of certain forms of content that are being communicated" [18]. Findings are presented in the next part of the paper.

\section{FINDINGS}

The Steelhead Haven community was developed in the early 1960s and continued to grow; however, during the 1990s and 2000s smaller landslides did occur. At 10:37 a.m. on March 22, 2014 the community of Oso, Washington experienced a massive landslide. Although there are several types of landslides, the most dangerous are flows. The flow 
landslide that occurred in Oso did not leave people time to escape. Within moments, the entire community of Steelhead Haven was inundated with mud and debris. This catastrophic event claimed the lives of 43 residents, destroyed 40 structures including 30 homes and deeply impacted the entire town as well as the nearby community of Darrington. All of those that could have been saved were in fact rescued on the Saturday that the slide occurred. Additionally, bodies of the 43 victims killed as a result of this natural disaster were eventually recovered from the site. However, a lack of coordination between relief agencies left community members confused and angry.

\section{Confusion/Redundancy}

According to the focus group respondents, the residents of Oso dealt with a sometimes overwhelming amount of redundancy as they sought help. A married couple who lost their home in the landslide recounted their ordeal; they made the two and a half hour drive around Darrington to register for aid. According to this couple, "They kept saying, the Red Cross is going to be here, Red Cross, Red Cross and Red Cross. We waited, waited and waited, and they finally showed up, and they didn't have any information. Come back tomorrow, you know.....there were a lot of duplications. You know, we filled out this paperwork, well then you have to, well no we don't have that paperwork. So you have to do more paperwork, and"... Another respondent stated, "Well, the next day they had us down at SV, the hospital in Mt. Vernon and now it was through the fire department; no, it was the police department and one more department; we filled out paperwork. So there was no communication right there". Similar responses came from another respondent who indicated "they said you need to go back to the fire department and that's where they'll approve that you guys are ok. And so we went back and we did it at the fire department and the community center, and they told us that we would have to wait there... after spending the night. We went back the next morning and they had no information about us at all'".

Another respondent went on to add that she didn't know what she would have done if it weren't for her daughter's assistance which prompted Respondent 4 to add "there were still families dealing with the paperwork involved with aid and insurance one year after the mudslide".

\section{Lack of Community Input}

It is clear from those who participated in the focus group that they did not feel that the relief agencies were even listening to their needs. Respondent 9 stated this most clearly by saying: "I think that any feedback we would give to them, or we heard about how they were going to come in and take over, how they don't make any attempt to learn about the community they're coming into. And it would make a huge difference....Because they have their, their own protocols and procedures. That's what they know and they don't care about the rest".

This statement is illustrative of the perception of the relief agencies that was communicated by the Oso residents during the focus group. Respondent 4 stated, "I think it's, it's, it's hard for a small town to know the bigger scope of people that are trying to come into town, but boy when you do see that face you know from another group or someplace else, it goes a long way".

There appeared to be a lack of correlation between where money was being spent and where the community would like it to be spent. One respondent stated, "There seems to have been a time for most people if you came up to them and asked them, how are you doing, they wanted to smack you; they were just tired. Everyone meant well, but it was just overload and the timing was not right. There were trust issues; you just knew that walls went up and went up".

Another respondent stated the following: "I think on a broader level if you're looking at the, you know, 35,000 foot level, inter-agency discussions; inter-agency talking to the locals is paramount in disasters. It doesn't happen enough from what I've seen. What do you need? What do you want? How do you want to see this unfold?"

An exchange during the focus group indicated that there were families that had been displaced by the mudslide who wanted to move back but have been unable to find land to purchase: "We'd like to find some opportunities to get those folks back on the earth there, but marijuana growers keep buying all the dirt up, so it's kind of a hard deal"... Another respondent stated "Yeah, Catholic Community Services was looming into that; yeah, yeah they wanted to put housing in". "We were pushing that at a county level, but uh; we begged them, you know basically". According to another respondent, "There are some folks that the Red Cross is like a swear word because of the change in the valley. And you don't say Red Cross around here pretty much at all". 


\section{Distress and Coping}

Focus group respondents expressed feelings of sadness and emotional distress after the mudslide. Consequently, respondents were still not ready to talk about their feelings with members of the community because of trust issues; they reported still experiencing emotional struggles. One respondent stated, "Even today you know that it comes and goes. It's a process. It is going to be a long time and we recognize that. But we're pretty fortunate that we've got good communication, support from our family and neighborhood. And we recognize that and so we use that. You know, we need to talk. We don't need to sleep; I've found that out. I always wake up at 2 o'clock every morning and then go back to bed...not sure yet, maybe one day I'll wake up and I'll know because I don't know how I feel now". This quote illustrates not only a difficulty with coping but a strategy for coping.

In addition survivors were coping differently. Coping strategies included increased drinking of alcohol, being silent and waking up in the middle of the night to try and process their feelings. Some of the residents started coping by drinking more because of lack of social support. Some respondents expressed fears. Negative coping mechanisms resulted in marital problems for several couples in the community. The following is a quote from one respondent: "If you're not communicating, not opening up and understanding that this is an issue; this is a real problem. It's just going to get worse and unfortunately in many cases it is worse". Another respondent added, "There are some pretty stoic people in the valley who are going to grin and bear it; they will drink it out and it'll bite them or not".

\section{Lack of Area Landslides}

The next theme that emerged was a high level of knowledge on local landslides. The residents of Oso who participated in the focus group had witnessed a large number of smaller landslides over the course of their time living in the area. According to one respondent, "I think that I personally see it on my property; it changes a little bit every year". An additional exchange revealed even more information. "Behind the, behind the place where I worked and lived we had a fill slide in 09 during the big rainstorm and snowstorm in January that happened. We've seen slides; there was that slide we just saw a couple of years ago; it was just down the road here, seen the cut out of that". Another respondent commented, "You know there's that spot (name omitted) when you cross Montague Creek, right underneath the power line. Have you noticed that? Every few years that one spot has failed"... "But that's how this whole valley is, so we never get alarmed about it".

\section{Sense of Community}

The final theme that emerged was that there was, and still is, a strong sense of community among Oso residents as evidenced by the following comments: "Fortunately we have each other and the communication level is tremendous. We all know each other and we all understand what everyone else is going through. We have a network of what's happening". Another respondent stated, "A lot of times they step in and the local community says, "Oh FEMA'S here. We're stepping back; we're not going to do anything. They're here and they're going to do everything. And that wasn't going to happen here. This is our town; these are our people. These are our machines and our knowledge".

\section{DISCUSSION}

The lack of coordination among groups responding to a natural disaster poses a serious threat to the overall success of the relief and reconstruction effort. If the goal of a relief effort is to aid the people on the ground, then expediency in getting aid to community members should be of utmost concern. Olshansky and Johnson (2015) stated that unfortunately a lack of coordination seems to be common in the U.S. following these events, as evidenced by the relief efforts following Hurricane Rita and Katrina in 2005 [19]. There was confusion and redundancy following the 2014 mudslide in Oso, WA rather than coordination of relief efforts by organizations such as the Red Cross.

The delayed response and ensuing confusion on the part of residents could have been alleviated by the use of local aid groups that are familiar with the affected area as well as those who live there. As aid became available these same community-based aid groups would be able to distribute money to support projects aimed at rebuilding infrastructure for those directly affected by the disaster if they choose to do so. The MDF in Indonesia was distributed in this manner successfully and on a much larger scale than that of Oso.

One of the benefits of a CDD approach is that due to the community involvement in the planning and implementation of projects, people have a vision of a tangible outcome and can see progress from the very beginning of the process. Fang (2006) showed that participants in CDD programs have stated that they had a positive feeling about 
the program because it gave them something to work for and made them feel that their voices were heard [20]. The opposite occurred in Oso.

Following a widely publicized disaster such as the 2014 mudslide in Oso, there is an outpouring of generosity from people near and far from the affected area. Support for the residents of Steelhead Haven came in from throughout Washington State and beyond.

If the community had a say over the way funds were distributed, based on the information from the focus group, it would seem likely to have made an effort to develop a housing project in order to bring displaced residents back to their community.

A large number of the financial donations made were to the Red Cross; a common practice of this organization is to solicit donations for its' Disaster Relief Fund. Following the Oso mudslide, the American National Red Cross (2014) stated on its website, "The best way to help is through a financial donation to the Red Cross Disaster Relief...Donations will be used to prepare for, respond to and help people recover from disasters big and small. This help will include the Oso landslide and nearly 70,000 other disasters we handle every year around the country" [21]. The Red Cross fulfills a role that may be lacking in most local planning; however, there is reason to ask whether someone seeing the devastation of a particular community and making a donation to an organization has a reasonable expectation that his or her money will actually go to the victims of the disaster. Many people are motivated to make donations to disaster funds because they want their donations to go directly to the victims rather than to a general operating fund.

The arguments against the World Bank's top down approach led to the development of the CDD approach. The complaints against the Red Cross as well as FEMA that came up during the focus group have the same tone. Top down approaches appear to be ineffective at meeting the needs of those most affected in a disaster while community-driven approaches have proven effective.

Given the complications that are inherent in the aftermath of any natural disaster, effective planning must be carefully undertaken in advance of a devastating event. As highlighted by Gore and Fischer (2014), environmental assessments added to disaster planning can be incredibly beneficial. A community-driven approach to the expanding and refining of geohazard mapping would add substantially to its effectiveness [22].

Eye witness accounts, such as those of the focus group respondents, have been shown to be incredibly effective at identifying critical areas for mitigation through Anderson and Holcombe's work in the Caribbean. According to Keller (2011), slopes which have experienced a previous slide are prone to reactivate in the future. In this respect, incorporating the firsthand accounts of residents such as those in the Oso focus group offers the opportunity to address areas that have a high likelihood to slide again, thus providing a clearer understanding of the true nature of the hazard [23]. Gore and Fischer (2014) identified the importance of environmental impact assessments for disaster planning prior to an event taking place and these firsthand accounts should be included in those assessments. By establishing through policy that relief efforts are to utilize a community-driven approach, information provided by residents would take on a higher level of importance in planning decisions.

The case of Oso illustrated the need for national organizations to recognize local residents as valuable resources. In Oso the residents were not only resources for knowledge of local terrain and conditions but also the key resources for post-disaster community resilience. The focus group respondents made repeated reference to instances where community input was not taken into account. This was illustrated in comments such as those regarding the failed attempt to build housing to bring back community members who had lost their homes in the landslide. These failures to include local stakeholders in the planning process led to a lack of trust as well as anger with relief agencies. Members of a given community, particularly in rural areas such as Oso, know what the community is in need of; therefore, they are better suited to address those needs than agencies from outside the community. A community-driven approach would have allowed the sense of community already present in Oso to be harnessed and utilized in the relief effort.

Accepting that communities consist of not only a territorial element but also a social element of equal, perhaps even greater importance, leads to very significant implications. In properly addressing the needs of a community, disaster relief policies must take into account the nature of both the hazard and the community resources available to relief agencies including local residents themselves. CDD projects have elicited a positive feeling in participants regarding the outcome and the effect on the community. The benefit offered in terms of community resiliency immediately following a disaster cannot be understated. If the goal of a relief or rebuilding process is to return normalcy and functionality to those affected outside agencies such as FEMA and the Red Cross must include community members in their decision- 
making protocols. This is where the strength of a community-driven approach arises. It should become part of the organization's operational protocols to involve community members in all efforts of the relief and rebuilding stages. The focus group responses illustrate that the strong sense of community that existed in Oso prior to the mudslide was of great help in the immediate aftermath as well as nearly a year later when the focus group was convened. A communitydriven approach would utilize this intangible sense of community as a valuable resource for the long term benefit of the members of the Oso community.

\section{CONFLICT OF INTEREST}

The authors confirm that this article content has no conflict of interest.

\section{ACKNOWLEDGEMENTS}

Declared none.

\section{REFERENCES}

[1] Projects and Operations. Available at: http://worldbank.org/en/topic/communitydrivendevelopment/projects/all 2013 [accessed March 03, 2015];

[2] World Health Organization. Recommendations for Mental Health in Aceh Recommendations for Mental Health in Aceh, Available at: http://cimh.unimelb.edu.au/_data/assets/pdf_file/0006/33945/WHO_Recommendations_for_MH_inAceh.pdf 2005 [accessed on March 3, 2015];

[3] Munashinghe M. The importance of social capital: comparing the impacts of the 2004 Asian Tsunami on Sri Lanka and hurricane katrina 2005 on New Orleans. Ecol Econ 2007; 64(1): 9-11. [http://dx.doi.org/10.1016/j.ecolecon.2007.05.003]

[4] Wickrama KA, Kaspar V. Family context of mental health risk in Tsunami-exposed adolescents: findings from a pilot study in Sri Lanka. Soc Sci Med 2007; 64(3): 713-23.

[http://dx.doi.org/10.1016/j.socscimed.2006.09.031] [PMID: 17084953]

[5] Weissbecker L, Jones L. International response to natural and manmade disasters. In: Okpaku SO, Ed. Essentials of Global Mental Health. London: Cambridge University Press 2014; pp. 326-35. [http://dx.doi.org/10.1017/CBO9781139136341.037]

[6] Wartman J. What We've Learned from Deadly Oso, Washington Landslide Two Years On. Seattle, WA: University of Washington 2016.

[7] Frazer E. The Problems of Communitarian Politics: Unity and Conflict. Oxford: Oxford University Press 1999. [http://dx.doi.org/10.1093/0198295642.001.0001]

[8] Gusfield JR. Community: A Critical Response (1st English Language ed) . New York: Harper \& Row 1975.

[9] McMillan DW, Chavis DM. Sense of Community: A Definition and Theory. J Community Psychol 1986; 14(1): 6-23. [http://dx.doi.org/10.1002/1520-6629(198601)14:1<6::AID-JCOP2290140103>3.0.CO;2-I]

[10] Cohen AP. The symbolic construction of community. New York: Tavistock Publication and Ellis Horwood Limited 1985. [http://dx.doi.org/10.4324/9780203323373]

[11] The World Bank. Projects and Operations. Available at: http://www.worldbank.org/en/topic/communitydrivendevelopment/projects/all 2013. (accessed March 03, 2015)

[12] International Fund for Agricultural Development [IFAD]. In: Community-Driven Development Tools for Rural Development Programmes; IFAD: Rome. 2009.

[13] Lee D. 10 Years after Tsunami, Indonesian Children Still Traumatized The Seattle Times, December 242014.

[14] Bado N. Community-driven development: A viable approach to poverty reduction in rural burkina FASO. Afr Dev Rev 2012; 24(1): 34-40. [http://dx.doi.org/10.1111/j.1467-8268.2011.00303.x]

[15] Horowitz CR, Robinson M, Seifer S. Community-based participatory research from the margin to the main stream. Circulation 2009; 119: $2633-42$. [http://dx.doi.org/10.1161/CIRCULATIONAHA.107.729863] [PMID: 19451365]

[16] Oso, washington population: Census 2010 and 2000 map, demographics, statistics: Quick facts. Washington, DC: U.S. Census Bureau 2010.

[17] Bryman A. Social Research Methods. 2nd ed. Oxford: Oxford University Press 2004.

[18] Rubin A, Babbie ER. In Research Methods for Social Work. 8th ed. Belmont, CA,: Brooks/Cole Cengage Learning: 2014 ; pp. 660-73.

[19] Olshansky RB, Johnson LA. The evolution of the federal role in supporting community-driven recovery after U. S. disasters. J Am Plann Assoc 2014; 80(4): 9-11.

[http://dx.doi.org/10.1080/01944363.2014.967710]

[20] Fang K. Designing and implementing a community-driven development programme in Indonesia. Dev Pract 2006; 16(1): 74-9. [http://dx.doi.org/10.1080/09614520500450891] 
[21] Red cross supports washington families during difficult time. Washington, DC: ANRC Publication 2014.

[22] Gore T, Fisher TB. Uncovering the factors that can support and impede post-disaster EIA practice in developing countries: the case of Aceh province, Indonesia. Environ Impact Assess Rev 2014; 44: 67-75. [http://dx.doi.org/10.1016/j.eiar.2013.09.001]

[23] Keller E. Environmental Geology. Upper Saddle River, NJ: Pearson Prentice Hall 2011.

(C) Harris et al.; Licensee Bentham Open

This is an open access article licensed under the terms of the Creative Commons Attribution-Non-Commercial 4.0 International Public License (CC BY-NC 4.0) (https://creativecommons.org/licenses/by-nc/4.0/legalcode), which permits unrestricted, non-commercial use, distribution and reproduction in any medium, provided the work is properly cited. 